\title{
65 Yaş ve Üstü Kişilerde Kronik Konstipasyonun Yaşam Kalitesine Etkisinin Değerlendirilmesi
}

\author{
Evaluation the Effect of Chronic Constipation on the Quality of Life in People Aged 65 \\ Years and Older
}

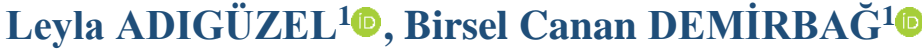 \\ ${ }^{1}$ Karadeniz Teknik Üniversitesi Sağlık Bilimleri Fakültesi, Trabzon, Türkiye
}

ÖZ

\begin{abstract}
Amaç: Kronik konstipasyon bağırsak fonksiyonlarının olumsuz yönde değişmesiyle günlük yaşam aktivitelerinin bozulmasına neden olan bir sağlık problemidir. Bu çalışmada 65 yaş ve üstü kişilerde kronik konstipasyonun yaşam kalitesine etkisinin belirlenmesi amaçlanmıştır.

Yöntem: Araştırmanın örneklemini Trabzon il merkezinde bulunan bir Aile Sağlığı Merkezi'ne bağlı bölgede yaşayan ve kronik konstipasyon tanısı almıș 65 yaş ve üzerindeki 125 birey oluşturmaktadır. Araştırmaya başlamadan önce etik kurul izni, kurum izni alınmıştır. Veriler literatür doğrultusunda oluşturulan demografik form, Kronik Konstipasyon Hasta Değerlendirme Ve Yaşam Kalitesi Ölçeği ve SF-36 Yaşam Kalitesi Ölçeği kullanılarak toplanmıştır. Araştırmadan elde edilen verilerin değerlendirilmesi frekans, yüzde, ortalama, ortanca, Pearson korelasyon testi kullanılarak yapılmıştır.

Bulgular: Kronik Konstipasyon Hasta Değerlendirme ve Yaşam Kalitesi Ölçeği puan ortalaması $40.57 \pm 15.66$ olarak belirlenirken SF-36 Yaşam Kalitesi Ölçeği fiziksel rol güçlüğü alt boyut puan ortalaması $15.58 \pm 16.84$ ve sosyal işlevsellik alt boyut puan ortalamas1 57.60 \pm 24.26 bulunmuştur. Bireylerin SF-36 Yaşam Kalitesi Ölçeği fiziksel fonksiyon, fiziksel rol güçlügü, emosyonel rol güçlüğü ve ağrı alt boyut puan ortalamaları ile Kronik Konstipasyon Hasta Değerlendirme Ve Yaşam Kalitesi Ölçeği puan ortalamaları arasında negatif yönlü anlamlı bir ilişki belirlenmiştir.

Sonuç: Bu çalışma kronik konstipasyonun yaşam kalitesini olumsuz yönde etkilediğini göstermiştir. Yaşlı bireylerin yaşam kalitesinin yükseltilmesi için konstipasyondan koruyucu sağlık davranışlarının bireylere öğretilmesi gerekmektedir.
\end{abstract}

Anahtar Kelimeler: Konstipasyon, Yaşam kalitesi, Yaşl1.

ABSTRACT

Objective: Chronic constipation is a health problem that causes disruption of daily life activities by changing intestine functions negatively. In this study, it was aimed to determine the effect of chronic constipation on the quality of life in people aged 65 years and over.

Methods: The sample of the study consists of 125 individuals aged 65 years and older who live in a region connected to a Family Health Center in Trabzon and are diagnosed with chronic constipation. Before starting the study, ethics committee permission and institution permission were obtained. The data were collected using the demographic form, the Chronic Constipation Patient Assessment and Quality of Life Scale, and the SF-36 Quality of Life Scale. The data obtained from the study were evaluated by using frequency, percentage, mean, median, Pearson correlation test.

Results: SF-36 Quality of Life Scale physical role strength subscale average score was found to be $15.58 \pm 16.84$ while the Individuals' Constipation Assessment Form average score was found to be $40.57 \pm 15.66$. It was also determined that there was a significant negative correlation between SF-36 Quality of Life Scale's physical function, physical role weakness, emotional role strength and pain subscales and average score of Constipation Assessment Scale.

Conclusion: This study has shown that chronic constipation affects quality of life negatively. Preventive health behaviors should be taught to individuals in order to raise the quality of life of elderly individuals.

Key words: Constipation, Life quality, Elderly.

Sorumlu Yazar: Leyla ADIGÜZEL

Karadeniz Teknik Üniversitesi Sağlik Bilimleri Fakültesi, Trabzon, Türkiye

leylaozkara@gmail.com

Geliș Tarihi: 13.06.2109 - Kabul Tarihi: 12.12.2019 


\section{GIiRiș}

Kronik konstipasyon, subjektif verilerle tanımlandığından kesin ve net bir tanımlaması olmamasının yanı sıra genel olarak bireylerin haftada iki ya da daha az dışkılaması olarak ifade edilmektedir. Kronik konstipasyon dışkılama sıklığındaki değişim ile birlikte birçok gastrointestinal sorunu da beraberinde getirmektedir. Dışkılama sıklığının değişmesinin yanı sıra karında huzursuzluk ve ağı, sert dışkı, gerginlik ve bulantı gibi birçok semptom kronik konstipasyona eşlik etmektedir (1-3). Ayrıca yaşlılık döneminin getirdiği hareketsizlik, kadın olmak, çoklu ilaç kullanımı ve sindirim sistemindeki değişimler gibi etmenler konstipasyon oluşmasına zemin hazırlamaktadır (4-6). Yaşlılarda kronik konstipasyonun dünyada görülme sıklığ $\% 40$ 'a kadar yükselirken, ülkemizde bu oran \%20 ile \%40 arasında değiş̧mektedir (7-9).

Kronik konstipasyon fiziksel, emosyonel ve sosyal iyilik haline büyük ölçüde etki eden ve yaşılıarda yaygın görülen bir problem olması nedeniyle günlük yaşam aktivitelerini zorlaştırmakta ve yaşam kalitesini etkilemektedir (8). Johanson ve Kralstein'ın çalışmalarında bireylerin \%52'sinde kronik konstipasyona bağlı yaşam kalitesinin bozulduğu ve bireylerin \%73'ünün kişisel ya da sosyal sorunlar yaşadıkları da ifade edilmektedir (10). Denisson ve arkadaşlarının çalışmasında ise kronik konstipasyon ile yaşam kalitesi arasındaki güçlü ilişkinin varlığı tespit edilmiştir (11).

Kronik konstipasyonun tedavisinde, yaşam kalitesini arttıran ve semptomları hafifletecek beslenme programlarının düzenlenmesi, yaşama hareket katılması ve tamamlayıcı tedavi uygulamaları gibi girişimler yer almaktadır $(5,6,12,13)$. Konstipasyon her yaş grubunda da problem olmasına rağmen özellikle fizyolojik değişimin yoğunlukla görüldüğü yaşlılık dönemindeki kişilerin yaşam kalitesine etkisi açısından daha da önem kazanmaktadır. Birinci basamak sağlık profesyonellerinin ve özellikle hemşirelerin kronik konstipasyon ile yaşamak zorunda kalan yaşlı bireylerin problemlerini azaltarak yaşam kalitesinin artırılmasına yönelik rehberlik yapmaları sağlık hizmetinin önemli boyutudur (14).

$\mathrm{Bu}$ çalışmanın amacı kronik konstipasyonun yaşlı bireylerin yaşam kalitesi düzeyine etkisini belirleyerek daha sonra yapılacak çalışmalara rehberlik etmektir.

\section{GEREÇ VE YÖNTEMLER}

Araştırmanın evrenini Trabzon il merkezinde bir Aile Sağlığı Merkezi'ne bağlı bölgede yaşayan ve kronik konstipasyon tanısı almış 65 yaş ve üzerindeki bireyler oluşturmaktadır. Araştırmaya başlamadan önce etik kurul izni (KTÜ Tip Fakültesi Bilimsel Araştırmalar Etik Kurulu, 24237859-507 ), kurum izni ve belirlenen kişilerle ev ziyareti yapılıp konunun amacı açıklanarak gerekli izinler alınmıştır. Bu Aile Sağlığı merkezine 12 Eylül 2017 ile 12 Ekim 2017 tarihleri arasında konstipasyon tedavisi için gelen belirlenmiş yaş grubuna ait bireylerle görüşülerek $(\mathrm{N}=125)$ çalışmayı kabul eden kişilerle $(\mathrm{n}=120)$ çalışma yapılmıştır. Çalışmada amaçlı örneklem yöntemi kullanılmıştır. Örneklemin tamamına bakıldığında \%97 güven aralığında çalışmanın örnekleminin yeterli olduğu görülmüştür. Veriler literatür doğrultusunda oluşturulan veri toplama formu, Kronik Konstipasyon Hasta Değerlendirme ve Yaşam Kalitesi Ölçeği ve SF-36 Yaşam Kalitesi Ölçeği kullanılarak toplanmıştır.

Kronik Konstipasyon Hasta Değerlendirme ve Yaşam Kalitesi Ölçeği kronik kabızlı̆̆ın yaşam kalitesi ve günlük yaşam aktiviteleri üzerindeki etkilerini ölçmek için geliştirilmiştir. Ölçek toplamda 28 soru ve "Fiziksel rahatsızlık", "Psikososyal rahatsızlık", "Kaygılar-uyarılar" 
ve 'Tatminlik' olmak üzere 4 alt boyuttan oluşmaktadır. Ölçekte her bir seçenek en az '0'ile en fazla '4' arasında bir puan almaktadır. ' 0 ' en düşük puanı '4' ise en yüksek puanı ifade etmektedir. Beşli Likert tipindeki ölçekten alınabilecek en yüksek puan 140, en düşük puan 28'dir. Ölçekten alınan puanlar yükseldikçe yaşam kalitesinin de olumsuz etkilendiği düşünülmektedir $(15,16)$.

SF-36 Yaşam Kalitesi ölçeğinin Türkçe geçerlilik ve güvenilirlik çalışması Koçyiğit ve arkadaşları tarafından yürütülmüştür. Ölçek fiziksel fonksiyon, rol güçlüğü, vitalite, sosyal fonksiyon, ağrı ve mental sağlık ve genel sağlı̆̆ı ölçmek üzere 36 sorudan meydana gelmektedir. Alt ölçekler sağlı̆̆ 0 ile 100 arasında değerlendirmektedir ve 0 kötü sağlık durumunu içerirken, 100 iyi sağlık durumuna işaret etmektedir (17).

Araştırmadan elde edilen verilerin değerlendirilmesi frekans, yüzde, ortalama, ortanca, Pearson korelasyon testi kullanılarak yapılmıştır.

\section{BULGULAR}

Araştırmaya katılan 120 bireyin yaş ortalaması $71.06 \pm 6.72$ olup katılımcıların $\% 73.3$ 'ü kadın, \%26.7'si erkektir. Katılımcıların \%67.5'i evli, \%30.8'i boşanmış/dul ve \%1.7'si bekardır. Katılımcıların \%44.2'si okuryazar değil, \%23.3'ü ilkokul mezunu, \%22.5'i okuryazar, \%5.0'i ortaokul mezunu, \%4.2'si lise mezunu ve \%0.8'i üniversite mezunudur. Çalışmaya katılan bireylerin \%82.5' inin geliri giderine denk, \%9.2'sinin geliri giderinden fazla ve \%8.3'ünün geliri giderinden azdır. Katılımcıların \%46.7'si il merkezinde, \%36.7'si ilçede ve \%16.7'si köyde yaşamaktadır. Katılımcıların \%98.3'ünün sağlık güvencesi bulunmaktadır (Tablo 1).

Tablo 1. Katılımcıların Demografik Verileri ( $N=120)$

\begin{tabular}{|c|c|c|c|}
\hline & & $\%$ & $\mathrm{n}$ \\
\hline \multirow{2}{*}{ Cinsiyet \% (n) } & Kadın & 73.3 & 88 \\
\hline & Erkek & 26.7 & 32 \\
\hline \multirow{2}{*}{ Medeni durum \% (n) } & Evli & 67.5 & 81 \\
\hline & Bekar & 32.5 & 39 \\
\hline \multirow{6}{*}{ Eğitim Durumu \% (n) } & Okuryazar değil & 44.2 & 53 \\
\hline & Okuryazar & 22.5 & 27 \\
\hline & İlkokul mezunu & 23.3 & 28 \\
\hline & Ortaokul mezunu & 5.0 & 6 \\
\hline & Lise mezunu & 4.2 & 5 \\
\hline & Üniversite mezunu & 0.8 & 1 \\
\hline \multirow{3}{*}{ Gelir Durumu \% (n) } & Geliri giderine denk & 82.5 & 99 \\
\hline & Geliri giderinden fazla & 9.2 & 11 \\
\hline & Geliri giderinden az & 8.3 & 10 \\
\hline Yaş ortalaması mean \pm sd & $71.06 \pm 6.72$ & & \\
\hline
\end{tabular}


Katılımcıların \%83.3'ü hastalığı nedeniyle ilaç kullanmaktadır. Kronik konstipasyon süresi ortalaması $3.45 \pm 0.36$ yıl olup, katılımcıların \%18.35'i 1 yıldan kısa süredir, \%37.5'i 1-3 yıl aras1, \%25.8'i 3-5 y1l aras1, \%18.35'i ise 5 y1ldan uzun süredir konstipe olduklarını bildirmişlerdir.

Hareket durumlarına bakıldığında katılımcıların \%82.5'i bağımsız hareket etmekte, \%16.7'si yardımla yürümekte, \%0.8'i ise yatağa bağlıdır. Egzersiz yapma sıklığına bakıldığında, katılımcıların \%30.0'u hiç egzersiz yapmamakta, \%64.2'si bazen egzersiz yapmakta, \%5.8'i ise sıklıkla egzersiz yapmaktadır (Tablo 2).

Tablo 2. Katılımcıların Hareket Durumlarına İlişkin Veriler (N=120)

\begin{tabular}{llcc}
\hline & & $\%$ & $\mathrm{n}$ \\
\hline \multirow{2}{*}{ Hareket durumu } & Bağımsız Hareket Ediyorum & 82.5 & 99 \\
\cline { 2 - 4 } & Yardımla Yürüyorum & 16.7 & 20 \\
\cline { 2 - 4 } & Yatağa Veya Sandalyeye Bağlı & 0.8 & 1 \\
\hline Egzersiz sıklığı & Hiç & 30 & 36 \\
\hline & Bazen & 64.2 & 77 \\
\hline & Sürekli & 5.8 & 7 \\
\hline
\end{tabular}

Katılımcıların \%71.7'si günde üç ve üzeri, \%25.8'i günde iki, \%2.5'i günde bir ögün yemek yemektedir. Katılımcıların \%31.7'si her öğün sebze meyve tüketirken, \%41.7'si haftada 3-4 öğün, \%26.7'si haftada 3 ögünden az sebze meyve tüketmektedir. Katılımciların $\% 67.5$ 'inin öğün saatleri düzenli \%32.5'inin ise düzensiz olduğunu belirlenmiştir. Katılımcıların \%96.7'si düzenli olarak kahvaltı yapmaktadır.

Araştırmaya katılan bireylerin \%27.5'i 4 bardak veya daha az, \%37.5'i 5bardak, \%22.5'i 6-9 bardak, \%12.5'i 10 bardak su tüketmektedir.

Katılımc1ların \%50.0'si alaturka tuvalet, \%45.0'i klozet, \%4.2'si oturaklı sandalye ve $\% 0.8$ 'i yatak pedi kullanmaktadır. Katılımcıların \%93.3'ü kullandıkları tuvaletin ortak tuvalet olduğunu, \%6.7'si tuvaletin kendine ait olduğunu belirtmişlerdir. Gün içerisinde dışkılama zamanına bakıldığında, \%50.8'inin sabah, \%40.0'ının öğünden sonra ve \%9.2'sinin diğer bir zamanda dışkıladıkları belirlenmiştir. Katılımcıların \%18.3'ünün her zaman dışkısının sert olduğu, \%75.8'inin dışkısının bazen sert olduğu ve \%5.8'inin ise dışkısının hiçbir zaman sert olmadığı kaydedilmiştir. Katılımcıların \%9.2'si dışkılarken her zaman makatta engellenme hissi yaşamakta, \%81.7'si dışkılarken bazen makatta engellenme hissi yaşamakta, \%9.2'si dışkılarken makatta engellenme hissi yaşamaktadır. Katılımcıların \%11.7'si dışkılama yaparken her zaman karına ve makata baskı uygularken, \%60.8'i dışkılama yaparken bazen karına ve makata baskı uygulamakta, \%27.5'i ise dışkılama yaparken karına ve makata baskı uygulamaktadır. Katılımcıların \%14.2'sinin dışkılama yaparken her zaman makatta ağrı hissettiğini, \%67.5'inin dışkılama yaparken makatta bazen ağrı hissettiği belirlenmiştir

Katılımcıların Kronik Konstipasyon Hasta Değerlendirme Ve Yaşam Kalitesi ölçek puan ortalaması $40.57 \pm 15.66$ olarak bulunmuştur.

Katılımcıların yaşam kalitesini incelemek için SF36 (Short Form 36) olarak adlandırılan yaşam kalitesi ölçeği kullanılmıştır. Ölçek alt boyut puanlarına bakıldığında, katılımcıların fiziksel fonksiyon alt boyut puan ortalaması 42.41 \pm 27.53 , fiziksel rol güçlüğü ölçek alt boyut puan ortalaması $38.95 \pm 42.10$, emosyonel rol güçlüğ̈̈ alt boyut puan ortalaması $43.33 \pm 44.61$, enerji alt boyut puan ortalaması $42.29 \pm 17.91$, sosyal işlevsellik alt boyut puanı ortalaması 
$57.60 \pm 24.26$, ağrı alt boyut puan ortalaması $58.79 \pm 20.84$ ve genel sağlık alt boyut puan ortalamas $44.29 \pm 16.41$ olarak bulunmuştur (Tablo 3).

Tablo 3. Katılımcıların SF36 Ölçek Puan Ortalamaları

\begin{tabular}{ll}
\hline Alt Boyut & $X \pm \mathrm{Ss}$ \\
\hline SF36 fiziksel rol güçlüğ̈̈ ölçek alt boyutu & $38.95 \pm 42.10$ \\
\hline SF36 enerji alt boyutu & $42.29 \pm 17.91$ \\
\hline SF36 fiziksel fonksiyon alt boyutu & $42.41 \pm 27.53$ \\
\hline SF36 emosyonel rol güçlüğü alt boyutu & $43.33 \pm 44.61$ \\
\hline SF36 genel sağlık alt boyutu & $44.29 \pm 16.41$ \\
\hline SF36 sosyal işlevsellik alt boyutu & $57.60 \pm 24.26$ \\
\hline SF36 ağr1 alt boyutu & $58.79 \pm 20.84$ \\
\hline SF36 ruhsal sağlik alt boyutu & $62.43 \pm 17.95$ \\
\hline
\end{tabular}

Katılımcıların kronik konstipasyon hasta değerlendirme ve yaşam kalitesi ölçek puan ortalamalarına bakıldığında kaygılar-uyarılar alt boyut puan ortalaması 16.64 \pm 7.74 iken Tatminlik alt boyut puan ortalaması $6.90 \pm 2.91$ olarak belirlenmiştir (Tablo 4).

Tablo 4. Katılımcıların Kronik Konstipasyon Hasta Değerlendirme Ve Yaşam Kalitesi Ölçek Puan Ortalamaları

\begin{tabular}{lc}
\hline Alt Boyut & $\mathrm{X} \pm \mathrm{Ss}$ \\
\hline Fiziksel rahatsızlık & $7.07 \pm 3.27$ \\
\hline Psikososyal rahatsılık & $9.95 \pm 6.31$ \\
\hline Kaygilar-uyarılar & $16.64 \pm 7.74$ \\
\hline Tatminlik & $6.90 \pm 2.91$ \\
\hline
\end{tabular}

Konstipasyon ölçek puanı ve SF-36 fiziksel fonksiyon alt boyutu arasındaki ilişki incelendiğinde aralarında negatif bir korelasyon olduğu belirlenmiştir (pearson korelasyon katsayısı r: -0.366). Bu korelasyon değeri, konstipasyon ölçek puanı ve fiziksel fonksiyon alt boyutu arasındaki ilişkinin gücünün orta düzeyde olduğunu göstermektedir. Konstipasyon ölçek puanı arttıkça, katılımcıların fiziksel fonksiyon düzeyi azalmaktadır (Tablo 5).

Konstipasyon ölçek puanları ve SF-36 fiziksel rol güçlüğü alt boyutu arasındaki ilişki incelendiğinde aralarında negatif bir korelasyon olduğu belirlenmiştir (pearson korelasyon katsayısı r: -0.411). Bu korelasyon değeri, konstipasyon ölçek puanı ve fiziksel rol güçlüğü alt boyutu arasındaki ilişkinin gücünün orta düzeyde olduğunu göstermektedir. Konstipasyon ölçek puanı arttıkça, katılımcıların fiziksel rol düzeyi azalmaktadır. Belirleme katsayısı 16.89 olarak hesaplanmıştır. Konstipasyon ölçek puanı, fiziksel rol güçlüğü alt boyutundan alınan puanın yüzde 16.89'unu açıklamaktadır (Tablo 5).

Konstipasyon ölçek puanları ve SF-36 emosyonel rol güçlüğü alt boyutu arasındaki ilişki incelendiğinde aralarında negatif bir korelasyon olduğu belirlenmiştir (pearson korelasyon katsayısı r: -0.411). Bu korelasyon değeri, konstipasyon ölçek puanı ve emosyonel rol güçlüğü alt boyutu arasındaki ilişkinin gücünün orta düzeyde olduğunu göstermektedir. Konstipasyon ölçek puanı arttıkça, katılımcıların emosyonel rol düzeyi azalmaktadır. Belirleme katsayısı 16.89 olarak hesaplanmıştır. Konstipasyon ölçek puanı, emosyonel rol güçlüğü alt boyutundan alınan puanın yüzde 16.89'unu açıklamaktadır (Tablo 5). 
Konstipasyon ölçek puanları ve SF-36 enerji alt boyutu arasındaki ilişki incelendiğinde aralarında pozitif bir korelasyon olduğu belirlenmiştir (Pearson korelasyon katsayısı r: 0.140). $\mathrm{Bu}$ korelasyon değeri, konstipasyon ölçek puanı ve enerji alt boyutu arasındaki ilişkinin gücünün zayıf olduğunu göstermektedir. Belirleme katsayısı 1.96 olarak hesaplanmıştır. Konstipasyon ölçek puanı, emosyonel rol güçlüğü alt boyutundan alınan puanın yüzde 1.96'sını açıklamaktadır (Tablo 5).

Konstipasyon ölçek puanları ve SF-36 sosyal işlevsellik alt boyutu arasındaki ilişki incelendiğinde aralarında negatif bir korelasyon olduğu belirlenmiştir (Pearson korelasyon katsayısı r: -0.440). Bu korelasyon değeri, konstipasyon ölçek puanı ve sosyal işlevsellik alt boyutu arasındaki ilişkinin gücünün orta düzeyde olduğunu göstermektedir. Konstipasyon ölçek puanı arttıkça, katılımcıların sosyal işlevsellik düzeyi azalmaktadır. Belirleme katsayısı 19.36 olarak hesaplanmıştır. Konstipasyon ölçek puanı, emosyonel rol güçlüğü alt boyutundan alınan puanın yüzde 19.36'sını açıklamaktadır (Tablo 5).

Konstipasyon ölçek puanları ve SF-36 ağrı alt boyutu arasındaki ilişki incelendiğinde aralarında negatif bir korelasyon olduğu belirlenmiştir (Pearson korelasyon katsayısı r: -0.440). Bu korelasyon değeri, konstipasyon ölçek puanı ve ağrı alt boyutu arasındaki ilişkinin gücünün orta düzeyde olduğunu göstermektedir. Konstipasyon ölçek puanı arttıkça, katılımcıların ağrı düzeyi azalmaktadır. Belirleme katsayısı 19.36 olarak hesaplanmıştır. Konstipasyon ölçek puanı, ağrı alt boyutundan alınan puanın yüzde 19.36'sını açıklamaktadır.

Konstipasyon ölçek puanları ve SF-36 genel sağlık alt boyutu arasındaki ilişki incelendiğinde aralarında negatif bir korelasyon olduğu belirlenmiştir (Pearson korelasyon katsayısı r: -0.130). Bu korelasyon değeri, konstipasyon ölçek puanı ve genel sağlık alt boyutu arasındaki ilişkinin gücünün zayıf olduğunu göstermektedir. Belirleme katsayısı 1.69 olarak hesaplanmıştır. Konstipasyon ölçek puanı, genel sağlık alt boyutundan alınan puanın yüzde 1.69'unu açıklamaktadır (Tablo 5).

Tablo 5. Konstipasyon ölçek puanları ve SF-36 ölçeği alt boyutları arasındaki ilişkiler

\begin{tabular}{lcc}
\hline Konstipasyon ölçek puanı ve yaşam kalitesi alt boyutları arasındaki ilişkiler & $\begin{array}{c}\text { Pearson } \\
\text { korelasyon } \\
\text { katsayısı (r) }\end{array}$ & p \\
\hline Konstipasyon ölçek puanı ve fiziksel fonksiyon alt boyutu arasındaki ilişki & r: -0.366 & 0.000 \\
\hline Konstipasyon ölçek puanı ve fiziksel rol güçlüğü alt boyutu arasındaki ilişki & r: -0.411 & 0.000 \\
\hline Konstipasyon ölçek puanı ve emosyonel rol güçlüğ̈̈ alt boyutu arasındaki ilişki & r: -0.411 & 0.000 \\
\hline Konstipasyon ölçek puanı ve enerji alt boyutu arasındaki ilişki & r: 0.140 & 0.002 \\
\hline Konstipasyon ölçek puanı ve sosyal işlevsellik alt boyutu arasındaki ilişki & r: -0.440 & 0.000 \\
\hline Konstipasyon ölçek puanı ve ağrı alt boyutu arasındaki ilişki & r: -0.440 & 0.000 \\
\hline Konstipasyon ölçek puanı ve genel sağlı alt boyutu arasındaki ilişki & r:-0.246 & 0.007 \\
\hline Konstipasyon ölçek puanı ve ruhsal sağlık alt boyutu arasındaki ilişki & r-0.040 & 0.662 \\
\hline
\end{tabular}

\section{TARTIŞMA}

Çalışmamızda yaşlı bireylerin kronik konstipasyon nedeni ile yaşam kalitesinin ne düzeyde etkilendiğini ve kronik konstipasyon ile yaşam kalitesi arasındaki ilişkiyi belirlemek amacıyla yürütülmüştür. Yaşlılık fizyolojik değişikliklerin yoğun yaşandığı bir süreçtir. Her ne kadar birey bu süreci yavaşlatmak ve yaşam kalitesini artırmaya gayret gösterse de bir veya birden fazla hastalık kaçınılmaz olarak gelişebilmektedir (18). Bu dönemde hareketlerin 
yavaşlaması ile özellikle sindirim sisteminde meydana gelen değişiklikler konstipasyon gibi birçok probleme eğilimi arttırmaktadır (19). Nitekim çeşitli çalışmalar da yaşlılarda bir veya birden fazla kronik hastalığa işaret etmektedir (20). Araştırmamıza katılan yaşlı bireylerin \%86.7 sinde bir ya da birden çok hastalığın varlığı belirlenmiştir. Bu yönden araştırma literatür ile benzerlik göstermektedir.

Yaşlı bireylerde geri dönüşsüz meydana gelen fizyolojik değişiklikler ve yaşam tarzı değişiklikleri konstipasyonun uzun süreli ya da kronik olarak görülmesine neden olabilmektedir (22). Literatüre bakıldığında yapılan bir çalışmada bireylerin konstipasyon süre ortalaması 4.2 yıl olarak belirtilmiştir (10). Çalışmamıza katılan yaşı bireylerin ortalama konstipe olma süresinin 3.45 yıl olduğu tespit edilmiştir. Bu sürenin yaşlı bireylerin fiziksel aktivite düzeyleri, beslenme alışkanlıkları, kullandıkları ilaçlar ve mevcut hastalıkları ile ilişkili olduğu düşünülebilir.

Mahassadi ve arkadaşlarının kronik konstipasyonu olan Afrikalı bireylerde yürüttüğü çalışmada SF-36 ölçek alt boyut puanlarında düşüş bulunmuştur. Bizim çalışmamızda enerji ve ruhsal sağlık alt boyutlar puan ortalamaları bu çalışma sonuçlarından daha yüksek bulunurken diğer alt boyut puan ortalamaları daha düşük bulunmuştur. Mahassadi ve arkadaşlarının bu çalışmasında farklı yaş gruplarına ait bireylerle çalışılırken çalışmamızda sadece 65 yaş ve üzeri konstipasyonu olan bireylerle çalışılmıştır ve çalışmaların yöntemleri de farklılık göstermektedir. Sonuçlar arasındaki farklılık yöntem ve çalışılan yaş gruplarının farklılık göstermesi ile açıklanabilir.

Kronik konstipasyon yaşlı bireylerde ağrı, sosyal ilişkilerde/çalışma hayatında bozulma, sinirli olma ve çatışma yaşama gibi sorunlara yol açmaktadır. Hastalar mahremiyetlerinin zarar göreceği düşüncesiyle sağlık personeline konstipasyondan bahsetmemekte ve konstipasyon yaşam kalitesini önemli ölçüde etkileyene kadar gizli kalmaktadır. Literatürdeki çalışmalarda kronik konstipasyonun bireylerin sosyal, mesleki ve ailevi ilişkilerini etkilediği bu sebeple yaşam kalitesinde bozulmaya neden olduğu ortaya konulmuştur (1,3,17). Yürüttüğümüz çalışmada literatür ile benzer şekilde kronik konstipasyonu olan yaşlı bireylerin yaşam kalitesinde azalma olduğu, konstipasyona bağlı sorunların yaşam kalitesinin ağrı, fiziksel fonksiyonlar, emosyonel durum, ruhsal durum, enerji gibi boyutlarında olumsuz etkiler yarattığ görülmektedir. Yaşam kalitesindeki bu düşüş kronik konstipasyonun beraberinde kronik ağrıyı getiren, sosyal yaşantıyı sekteye uğratan, çalışma hayatında sorun yaratan, günlük yaşam aktivitelerini kısıtlayan ya da durduran bir sağlık sorunu olması ile açıklanabilir.

Yaşlı bireylerin kullandıkları ilaçların ve beslenmesinin sorgulanmaması ve bir aile merkezinde çalışılması araştırmanın sınırlılıklarını oluşturmaktadır

Sonuç olarak; kronik konstipasyon boşaltım fonksiyonlarının değişmesi sonucu günlük yaşam aktivitelerinin bozulmasına neden olarak yaşam kalitesini etkileyen bir sorundur. $\mathrm{Bu}$ çalışmada da bireylerin kronik konstipasyon nedeniyle yaşam kalitelerinde önemli düzeyde bir düşüş olduğu belirlenmiştir. Yaşam kalitesini yükseltmek ve bireylerin sosyal yaşama katılımını artırmak için sağlık personellerinin özellikle koruyucu sağlık hizmetlerinde aktif rol alan hemşirelerin konstipasyon gelişimini engelleyici girişimleri öğretmesi ve uygulaması gerekmektedir. 


\section{TEŞEKKÜR}

$\mathrm{Bu}$ çalışmanın istatistiksel analizlerinde katkı sağlayan Hülya ZENGİN’e teşekkür ederiz.

\section{Araştırmanın Etik Yönü}

Araştırmaya başlamadan önce etik kurul izni (KTÜ Tıp Fakültesi Bilimsel Araştırmalar Etik Kurulu, 24237859-507 ), kurum izni ve belirlenen kişilerle ev ziyareti yapılıp konunun amacı açıklanarak gerekli izinler alınmıştır.

\section{KAYNAKLAR}

1. Belsey, J., Greenfield, S., Candy, D., \& Geraint, M. (2010). Systematic review: impact of constipation on quality of life in adults and children. Alimentary Pharmacology \& Therapeutics, 31(9), 938-949.

2. Norton, C. (2006). Constipation in older patients: effects on quality of life. British Journal of Nursing, 15(4), 188-192.

3. Tvistholm, N., Munch, L., \& Danielsen, A. K. (2017). Constipation is casting a shadow over everyday life-a systematic review on older people's experience of living with constipation. Journal of Clinical Nursing, 26(7-8), 902-914.

4. Demirbaş, S. (2010). Kronik kabızlık nedenleri, tanı yöntemleri ve tedavi yaklaşımları. Gülhane Tip Dergisi, 52, 61-68.

5. Dukas, L., Willett, W. C., \& Giovannucci, E. L. (2003). Association between physical activity, fiber intake, and other lifestyle variables and constipation in a study of women. The American journal of gastroenterology, 98(8), 1790-1796.

6. Tufan, A., \& Akin, S. (2015). Yaşlıda Konstipasyon ve Fonksiyonel Dispepsi. Turkiye Klinikleri J Geriatr-Special Topics, 1(1), 95-99.

7. Akpınar, H. (2007). Kronik konstipasyon. Paper presented at the 7. Ulusal İç hastalıkları kongresi, Antalya.

8. Gallagher, P., \& O'Mahony, D. (2009). Constipation in old age. Best Practice \& Research Clinical Gastroenterology, 23(6), 875-887.

9. Türkay, C., Aydoğan, T., \& Özden, A. (2005). Konstipasyon tanım ve epidemiyolojisi. Güncel Gastroenteroloji, 9(1), 48-52.

10. Johanson, J., \& Kralstein, J. (2007). Chronic constipation: a survey of the patient perspective. Alimentary Pharmacology \& Therapeutics, 25(5), 599-608.

11. Dennison, C., Prasad, M., Lloyd, A., Bhattacharyya, S. K., Dhawan, R., \& Coyne, K. (2005). The health-related quality of life and economic burden of constipation. Pharmacoeconomics, 23(5), 461-476.

12. Kim, H. S., Park, D. H., Kim, J. W., Jee, M. G., Baik, S. K., Kwon, S. O., et al.. (2005). Effectiveness of walking exercise as a bowel preparation for colonoscopy: a randomized controlled trial. The American journal of gastroenterology, 100(9), 1964.

13. Lorenzo, B. G. E., \& Lorenzo, M. G. E. (2015). Liquid intake in elderly people. Nutrición Hospitalaria, 32(2), 31-32. doi:10.3305/nh.2015.32.sup2.10297

14. Tezel, A. (2017). Yaşlanmaya Bă̆ll Fizyolojik Değişimler. In N. Bilgili \& Y. Kitiş (Eds.), Yaşlılık Ve Yaşlı Sağlığı (pp. 76-87). Ankara: Vize Yayıncılık.

15. Bengi, G., Yalçın, M., \& Akpınar, H. (2014). Kronik konstipasyona güncel yaklaşım. Güncel Gastroenteroloji, 18(2), 181-197. 
16. Kaya, N., \& Turan, N. (2011). Konstipasyon Ciddiyet Ölçeğinin Güvenilirlik ve Geçerliliği. Turkiye Klinikleri Journal of Medical Sciences, 31(6), 1491-1501.

17. Simren, M., Svedlund, J., \& Posserud, I. (2006). Gastroenteroloji Polikliniğine Başvuran Hastalarda Sağlıkla İlişkili Yaşam Kalitesi: Fonksiyonel Bozukluklara Karşı Organik Hastalıklar. Clinical Gastroenterology and Hepatology, 1(1), 28-38.

18. Pehlivan, S., \& Karadakovan, A. (2013). Yaşlı Bireylerde Fizyolojik Değişiklikler Ve Hemşirelik Tanılaması. Gümüşhane Üniversitesi Să̆lık Bilimleri Dergisi, 2(3), 385395.

19. Beğer, T. (2003). Geriatrik yaş grubunda fizyolojik değişiklikler. Paper presented at the 5. Ulusal Iç Hastalıkları Kongresi, Antalya.

20. Bilgiç, Ş., Dilek, F., Arslan, H. S. A., \& Ünal, A. (2016). Bir Huzurevinde Yaşayan Yaşlilarin Konstipasyon Durumları ve Etkileyen Faktörler. International Journal of Basic and Clinical Medicine, 4(1), 9-16.

21. Yöntem, G. H., Türk, G., Khorsid, L., \& Eşer, İ. (2011). Huzurevinde kalan yaşlı bireylerde konstipasyon tanısının değerlendirilmesi. Florence Nightingale Hemşirelik Dergisi, 19(2), 83-88.

22. Tiftik, S., Kayış, A., \& İnanır, İ. (2012). Yaşlı bireylerde sistemsel değişiklikler, hastalıklar ve hemşirenin rolü. Akad Geriatri, 4(1), 1-11. 